\title{
Análise Exploratória da Socioeconomia de Sistemas Agroflorestais em Várzea Flúvio-Marinha, Cametá-Pará, Brasil ${ }^{1}$
}

\author{
Raimundo Nonato da Silveira Ribeiro ${ }^{2}$ \\ Antônio Cordeiro de Santana ${ }^{3}$ \\ Manoel Malheiros Tourinho ${ }^{4}$
}

Resumo - Este trabalho objetivou identificar e caracterizar o sistema de exploração da várzea flúvio-marinha em unidades de produção agroflorestal - UPA, nos aspectos florísticos e socioeconômicos. Utilizaramse as técnicas do inventário florestal, orçamentos unitários e questionários. Os resultados expressaram uma composição florística média de 2.920,7 indivíduos/ha com circunferência à altura do peito (CAP) $\geq 10$ $\mathrm{cm}$, com maiores frequência de açaí $(50,63 \%)$, cacau $(31,02 \%)$ e virola $(6,76 \%)$. O Sistema está constituído pela exploração florestal madeireira, não-madeireira, pesca e criação de aves e suínos. O custo anual do sistema agroflorestal - SAF é de R\$1.866,25/UPA e a renda bruta anual oriunda do SAF é de R\$2.959,08/UPA. Concluiu-se que o sistema é do tipo agrossilvipastoril, em que a atividade de criação de aves e suínos utiliza como fonte de alimentos a mariscagem na várzea. A tecnologia utilizada, em princípio, favorece a conservação e preservação do ecossistema, há todavia a necessidade de qualificação de mão-de-obra familiar. A renda bruta anual do SAF denota viabilidade econômica das

\footnotetext{
${ }^{1} \mathrm{O}$ artigo baseia-se em parte da dissertação de mestrado do primeiro autor, orientado pelo segundo e co-orientado pelo terceiro autor.

${ }^{2}$ Eng ${ }^{\circ}$ Agr $^{\circ}$ M. Sc. em Ciências Florestais e extensionista da EMATER-PARÁ, MaritubaPará - rionata@interconect.com.br

${ }^{3}$ Eng $^{\circ}$ Agr $^{\circ}$ D. Sc. em Economia Rural e Professor da UFRA - Belém-Pará - santana@ nautilus.com.br

${ }^{4}$ Eng $^{\circ}$ Agr $^{\circ}$, Ph. D. Professor Titular e Reitor da UFRA - Belém-Pará - gab@ufra.br
} 
UPA no nível do salário mínimo, porém, tais unidades são pluriativas, apresentando rendas múltiplas, cujas rendas não-agrícolas são fundamentais para a permanência das famílias na atividade e no meio rural.

Termos para indexação: Agricultura familiar, Amazônia, socioeconomia ribeirinha.

\section{Exploratory Socioeconomic Analysis of Agroforestry Systems in Tidal River Floodplains, Cametá, Pará, Brazil}

Abstract - The purpose of this paper is to identify and characterize forestry and socio-economic systems of tidal river floodplain utilization in agroforestry production units (UPA). Forest inventory techniques, budget sheets and questionnaires were utilized. The results obtained express an average floristic composition of 2,920.7 plants/ha, with a breast-high circumference $(\mathrm{CHC}) \geq 10 \mathrm{~cm}$, the highest frequency being for açaí (Euterpe oleracea) (50.63\%), cocoa (Theobroma cacau) (31.02\%) and virola (Virola surinamensis) (6.76\%). The system comprises timber and non-timber forest exploitation, fishing, and poultry and swine raising. The annual cost of the agroforestry system (SAF) is R\$1,866.25/UPA and annual gross income is $R \$ 2,959.08 /$ UPA. It was concluded that the system is an agro-silvi-pastoral one, where poultry and swine raising utilizes floodplain shellfish as feed source; in principle, the technology used is favorable to the ecosystem conservation; however, there is a need for improving the quality of family labor. The SAF annual gross income demonstrates the economic feasibility of the UPAs at a minimum wage level; however, such units are multi-functional and have multiple incomes whose non-agricultural earnings are fundamental to families persevering in this activity and staying in the rural environment.

Key words: Family agriculture, Amazonia, floodplain socioeconomy. 


\section{1 - Introdução}

As várzeas flúvio-marinhas do estuário do Rio Pará se encontram localizadas e distribuídas por um conjunto hidrográfico formado pelos rios Araguaia, Tocantins, Capim, Acará, Moju, Guamá, Anapu, Jacundá, Pacajás e Araticum. Os sistemas agroflorestais (SAF's) objeto do estudo estão localizados nas várzeas do Rio Juba, afluente do Rio Tocantíns, município de Cametá, Pará.

No ecossistema de várzea são desenvolvidas atividades econômicas em que se destacam cultivos agrícolas temporários e permanentes, exploração das florestas com extração madeireira e coleta de produtos não-madeireiros, criações de animais domésticos e pesca (Furtado, 1994; Imazon, 1998; Tourinho \& Nogueira, 1999; Ribeiro, 2002).

A várzea amazônica é um ecossistema rico e distinto no que se refere à biodiversidade e diversidade dos recursos naturais, com potencial de uso de madeira, castanha, borracha, palmito, frutos, essências aromáticas, sementes oleagisosas e pescados. Esse ecossistema possui cerca de 400 anos de exploração, com a população local mantendo uma forte inter-relação de dependência com o ambiente aquático e terrestre.

No caso da área de estudo, localizada à jusante da Usina Hidrelétrica de Tucurui, o ambiente terrestre, precisamente as florestas nativas, que vem originando as agroflorestas manejadas por famílias ribeirinhas, com a barragem do Rio Tocantins em 1984, assumiu uma importância singular na vida das famílias moradoras, fornecendo os alimentos básicos, ocupando a mão-de-obra familiar e possibilitando renda monetária, gerando a dependência dos SAF's para a sobrevivência.

Assim o estudo buscou conhecer alguns aspectos relacionados com a composição florística desses SAF's e com a socioeconomia familiar ribeirinha que sobrevive do ambiente de várzea. O objetivo foi identificar e caracterizar os SAF's existentes quanto aos aspectos de composição florística relacionados à produção de madeiras e produtos nãomadeireiros geradores de renda e/ou de uso familiar, tecnologias de produção utilizadas no manejo dos SAF's pelos agricultores ribeirinhos, bem como determinar a rentabilidade monetária da produção agroflorestal. 
Análise Exploratória da Socioeconomia de Sistemas Agroflorestais em Várzea Flúvio-Marinha, Cametá-Pará, Brasil

\section{2 - Metodologia}

A pesquisa foi desenvolvida em seis unidades de produção agroflorestal (UPA), conduzidas por agricultores familiares ribeirinhos. As UPA possuem tamanhos de áreas variando entre os limites de cinco a 60 hectares, que representam as dimensões das UPA na região de estudo.

A caracterização florística dos SAF's foi obtida com base no inventário florestal, realizado em parcela de 0,25 ha, dividida em 25 sub-parcelas de $10 \mathrm{~m}$ x $10 \mathrm{~m}$, por UPA, com identificação dos indivíduos a partir de dez $\mathrm{cm}$ de circunferência à altura do peito (CAP).

O uso atual dos SAF's, foi obtido através de observações de campo e entrevistas estruturadas com apoio de questionário.

O volume estimado de madeira foi determinado por equação de regressão linear simples, em conformidade com o método descrito por Queiroz (1994). Os custos e rendas foram determinados com base na técnica de orçamentos unitários, descritos em Hoffmann et al. (1978) e discriminados a seguir.

Os custos foram obtidos com base nos preços praticados na comunidade para serviços e insumos (ano 2000). Os custos fixos totais foram obtidos pela fórmula:

$\mathrm{CFT}=\sum_{j} P j Z j$, onde:

CFT $=$ custos fixos totais; $P_{j}=$ preço do bem de capital e mão-deobra permanente $\mathrm{j}$;

$Z_{j}=$ quantidade do bem de capital e mão-de-obra permanente $\mathrm{j}$ Os custos variáveis totais foram obtidos pela fórmula CVT $=\sum_{i} P_{i} X_{i}$
onde:

$\mathrm{CVT}=$ custos variáveis totais; $\quad=$ preço do insumo $\mathrm{i}$;

$X_{i}=$ quantidade do insumo i.

A renda bruta total da UPA é a somatória de todos os ingressos existentes, ou seja, a renda bruta originada do SAF dada pelo valor bruto da produção, inclusive aquela consumida na UPA, estimada segundo os 
preços praticados na comunidade, pela aposentadoria e outras fontes não-agrícolas. A renda bruta anual originada do sistema agroflorestal foi obtida através da fórmula: $R B S A F=\sum_{i} P_{i} Q_{i}$, em que: $R B S A F=$ renda bruta do SAF, medida em $\mathrm{R} \$ / \mathrm{UPA}$ e $\mathrm{R} \$ /$ ha;

$P_{i}=$ preço do produto i, medido em $\mathrm{R} \$$

$Q_{i}=$ quantidade do produto i.

A renda líquida anual dos SAF's pesquisados ou valor líquido da produção, foi obtida mediante a diferença entre os valores da renda bruta total anual dos SAF's e os custos totais anuais apurados por atividade componente do sistema de produção de cada UPA. A fórmula utilizada foi:

RLSAF $=$ RBSAF - CT, em que:

RLSAF = renda líquida, medida em $\mathrm{R} \$ / \mathrm{UPA}$ e $\mathrm{R} \$ / \mathrm{ha}$;

RBSAF = renda bruta anual dos SAF's, medida em R $\$ /$ UPA e R $\$ /$ ha;

$\mathrm{CT}=$ Custos totais apurados no período, em R $\$ / \mathrm{UPA}$ e $\mathrm{R} \$ / \mathrm{ha}$.

\section{3 - Resultados e Discussões}

\subsection{Caracterização geral da flora e do sistema de exploração}

A composição florística é diversificada, e constituída, em média, por 51 gêneros, 26 famílias e 59 espécies (Ribeiro, 2002). A média por hectare, é de 2.920,7 indivíduos com $\mathrm{CAP} \geq 10 \mathrm{~cm}$. Considerando a abundância absoluta, densidade relativa e a utilização pelos ribeirinhos, as famílias e espécies de maior representatividade na amostra de 1 hectare são: Aracaceae com 1.479 exemplares de açaizeiros (50,63 \% da população total), Sterculiaceae com 906 indivíduos cacaueiros (31,02\% da população total), a Myristicaceae com 197 indivíduos virola (6,76 \% da população), a Meliaceae com 76 plantas andirobeiras (2,62 \% da população) e a Fabaceae com 28 exemplares mututi (0,96 \% da população) (Tabela 1). 
- Análise Exploratória da Socioeconomia de Sistemas Agroflorestais em Várzea Flúvio-Marinha, Cametá-Pará, Brasil

Tabela 1 - Famílias e espécies vegetais mais representativas na estrutura fitossociológica horizontal dos SAF’s de várzea, Rio Juba afluente do Rio Tocantis, Cametá-PA 2001 - 1 ha

\begin{tabular}{lccrc}
\hline Nome vulgar & Nome científico & Família botânica & Abundância & $\begin{array}{c}\text { Densidade } \\
\text { relativa \% }\end{array}$ \\
\hline 1 - Madeireiras & & & \\
\hline - Virola & Virola surinamensis & Myristicaceae & 197,30 & 6,76 \\
- Andiroba & Carapa guianensis & Meliaceae & 76,70 & 2,62 \\
- Mututí & Pterocarpus amazonicus & Fabaceae & 28,00 & 0,96 \\
- Pracuúba & Mora paraensis & Moraceae & 6,70 & 0,23 \\
- Cajuí & Anacardium giganteum & Anacardiaceae & 6,00 & 0,21 \\
- Pitaíca & Swartzia acuminata & Caesalpiniaceae & 5,30 & 0,18 \\
- Mututirana & Pterocarpus officinalis & Fabaceae & 3,30 & 0,11 \\
- Ceruzeiro & Allantoma lineata & Lecythidaceae & 2,70 & 0,09 \\
- Cinzeiro & Terminalia amazonica & Combretaceae & 2,70 & 0,09 \\
\hline 2- Não-madeireiras & & & \\
\hline - Açaí & Euterpe oleracea & Arecaceae & $1.479,00$ & 50,63 \\
- Cacau & Theobroma cacao & Sterculiaceae & 906,00 & 31,02 \\
- Buriti & Mauritia flexuosa & Arecaceae & 10,00 & 0,34 \\
- Banana & Musa spp & Musacea & 6,70 & 0,23 \\
- Ingá & Inga paraensis & Mimosacea & 2,70 & 0.09 \\
\hline 3- Outras espécies & & & 187,60 & 7,304 \\
\hline Total & & & $2.920,70$ & 100,00 \\
\hline
\end{tabular}

Fonte: Ribeiro (2002)

A pesquisa identificou um sistema de exploração agroflorestal constituído por três atividades: a) florestal madeireira; b) florestal não-madeireira; c) pesca e criação extensiva de aves e suínos.

A atividade florestal madeireira é praticada em $100 \%$ das UPA, envolvendo as operações extrativas de madeiras em toras destinadas às serrarias ou para uso nas UPA.

A atividade florestal não-madeireira está constituída pelas operações de coletas de frutos de açaí, de cacau, frutos de buriti e sementes de andiroba, que são exploradas por $100 \%$ das famílias, cultivo de banana em 66,66 \% das UPA, extração do óleo de andiroba por 50 \% das unidades e, com menor frequência, entre $16,67 \%$ e 33,33 \%, estão as operações representadas pela coleta de sementes de virola, frutos de taperebá, e a extração de talas de jupati, buriti e marajá, destinadas à confecção de esteiras para secagem do cacau e confecção de instrumentos de pesca; A atividade de criação extensiva de aves e suínos utiliza como prin- 
cipal fonte de alimentos a mariscagem na várzea, ou seja, os animais percorrem as várzeas para catarem seus alimentos (mariscos, frutos e sementes) após os fluxos e refluxos das marés a cada 12 horas. É praticada por $83,33 \%$ das UPA estudadas, enquanto a pesca de camarões e de peixes é praticada por $100 \%$ e $66 \%$ das UPA respectivamente, cujos produtos são destinados à alimentação das famílias.

Pela natureza de sua constituição quanto aos produtos obtidos, quais sejam produtos madeireiros, agrícolas e criatórios, tem-se um sistema de exploração agrossilvipastoril.

\subsubsection{Tecnologia de manejo e produção do sistema de exploração agroflorestal}

No manejo florestal madeireiro, as operações mais relevantes, do ponto de vista de tornar mais fácil a extração de madeiras, garantir o estoque de espécies de valor econônico ou de uso nas UPA, são: roçagem de limpeza e manutenção da agrofloresta manejada; repicagem de plântulas nativas de andiroba e virola; corte de árvores e transportes das toras para serraria e/ou uso nas UPA; e corte e transporte de árvores para uso como lenha e/ou carvão.

Esta atividade ocupa mão-de-obra em todos os meses do ano. A operação de corte e transporte da madeira do interior da agrofloresta para uso como lenha e/ou fabricação de carvão, ocupa 16,72 \% (44,33 dias/ homem/ano) de toda a mão-de-obra requerida pelo sistema de produção. A operação de corte e transporte de árvores em toras destinadas às serrarias da localidade e/ou uso na UPA, está distribuída de janeiro a abril, com ocupação média anual de 2,89 \% (7,67 d/h ano) da demanda total do sistema; enquanto as operações de repicagem de plântulas de andiroba e virola, ocupam a média anual de 0,6 \% (1,58 d/h ano) do total do sistema. O período de julho a novembro é o de menor demanda de mão-de-obra. A atividade madeireira necessita, em média anual por UPA, de 53,58 d/h (Ribeiro 2002), o que representa 20,2 \% da média da mão-de-obra total requerida pelo sistema. As espécies madeireiras mais frequentemente destinadas à venda para serrarias e/ou uso nas UPA, estão especificadas na Tabela 2 e as preferidas como lenha e/ou carvão estão especificadas na Tabela 3. 
Tabela 2 - Espécies florestais madeireiras mais utilizadas pelas serrarias e uso nas UPA estudadas, Rio Juba afluente do Rio Tocantíns, Cametá-PA - 2001

\begin{tabular}{lccc}
\hline Nome vulgar & Nome científico & Uso na UPA & DAP corte $^{\mathbf{1}-\mathbf{c m}}$ \\
\hline Ananí & Symphonia globulifera & Habitação & 30 \\
Andiroba & Carapa guianensis & Embarcação, habitação e lenha & 30 \\
Assacú & Hura creptans & - & 100 \\
Cinzeiro & Terminalia amazonica & Habitação, lenha e carvão & 30 \\
Faveira & Vatairea guianensis & Habitação & 30 \\
Ipê-da-várzea & Macrolobium sp & Embarcação, habitação e móveis & 30 \\
Jaraí vermelho & Sarcaulus brasiliensis & Embarcação e habitação & 20 \\
Maúba & Licania mahuba & Embarcação, habitação e móveis & 20 \\
Mangonçalo & Hieronima alchornoides & Habitação, lenha e carvão & 30 \\
Munguba & Pseudobombax munguba & Habitação & 45 \\
Panarí & Parinari coriaceum & Embarcação & 50 \\
Pracuúba & Mora paraensis & Embarcação, habitação e lenha & 50 \\
Aquariquara & Minquartia guianensis & Habitação & 30 \\
Seruzeiro & Allantoma lineata & Habitação & 30 \\
Sucupira-da-ilha & Bowdichia sp & Habitação, pontes e trapiches & 30 \\
Virola & Virola surinamensis & Habitação e lenha & 30 \\
\hline
\end{tabular}

Fonte: Ribeiro (2002)

Obs: ${ }^{1}$ DAP $=$ Diâmetro à altura do peito.

Tabela 3 - Espécies florestais madeireiras preferidas para lenha e/ou carvão nas UPA estudadas, Rio Juba afluente do Rio Tocantíns, Cametá-PA - 2001

\begin{tabular}{lcc}
\hline Nome vulgar & Nome científico & DAP de corte $^{\mathbf{1}} \mathbf{- c m} \mathbf{~ c m}$ \\
\hline Acapurana & Campsiandra laurifolia & 10 \\
Anauerá & Licania macrophyla & 10 \\
Capoteiro & Stetculia speciosa & 10 \\
Cinzeiro & Terminalia amazonica & 30 \\
Imbaúba & Cecropia palmata & 30 \\
Ingarana & Pithecollobium latifolium & 10 \\
Ingá & Inga paraensis & 10 \\
Mututí & Pterocarpus amazonicus & 10 \\
Pacapeuá & Swartzia racimosa & 10 \\
Pitaíca & Swartzia acuminata & 10 \\
Pracaxí & Pentaclethra macroloba & 10 \\
\hline
\end{tabular}

Fonte: Ribeiro (2002)

Obs: ${ }^{1}$ DAP $=$ Diâmetro à altura do peito. 
No manejo florestal não-madeireiro, foram identificadas operações para facilitar o deslocamento interno das pessoas e reduzir riscos de acidentes; aumentar o rendimento das espécies frutíferas e garantir a existência das espécies usadas como alimentos e geração de rendas. As operações são: roçagem de limpeza e desbaste de touceiras de açaí; repicagem de plântulas nativas de açaí e cacau; colheita e transporte dos frutos de açaí do interior da agrofloresta; extração e transporte de palmitos de açaí; colheita de frutos de banana; colheita, transporte e corte de frutos de cacau; coleta, transporte e extração de óleo de sementes de andiroba; coleta de sementes de virola; coleta de frutos de buriti e de taperebá e extração de talas de jupati, de buriti e de marajá.

De forma semelhante à atividade florestal madeireira, a atividade não-madeireira demanda mão-de-obra no decorrer de todo o ano. A distribuição mensal do uso da mão-de-obra, obtido no processo de entrevista, evidenciou que os meses de fevereiro, maio, junho, julho, agosto, outubro e dezembro são os que mais ocupam mão-de-obra, o que se explica pelas operações de manejo que ocorrem nesse período, com destaque para as operações de roçagem de limpeza da área e desbaste de touceiras de açaí, que demandam a média anual por UPA de $58 \mathrm{~d} / \mathrm{h}$, representando $21,87 \%$ do total requerido pelo sistema de produção. Esta é a operação que mais utiliza mão-de-obra, seguida pela colheita de açaí, com uma média anual de 55,167 d/h equivalente a 20,81 \% do total requerido pelo sistema.

Ainda na atividade não-madeireira, pode-se citar as operações de coleta de frutos diversos (buriti, taperebá, virola, etc), coleta e transporte de sementes de andiroba e colheita e transporte de cacau, com demandas médias anuais de 10,75, 8,916 e 8,25 d/h, respectivamente.

No sistema de produção, a atividade florestal não-madeireira possui uma demanda média anual por UPA de 152,25 d/h ano, que representam $57,41 \%$ da mão-de-obra total.

A mão-de-obra familiar participa de todas as operações da atividade florestal não-madeireira. Quanto à mão-de-obra contratada temporária, os meses do ano com maior representatividade são os meses de julho, com 14,89 d/h e junho, com $8,12 \mathrm{~d} / \mathrm{h}$, seguidos por dezembro, janeiro e fevereiro com ocupações médias de 3,81 d/h, 3,43 d/h e 3,02 $\mathrm{d} / \mathrm{h}$, respectivamente, que são exatamente aqueles onde ocorrem as 
operações de roçagem de limpeza da área e desbaste de touceiras de açaí, extração de palmitos e as colheitas de açaí e cacau. A utilização da mão-de-obra contratada, nesta atividade, é bastante significativa, apresentando uma média anual por UPA de $47,37 \mathrm{~d} / \mathrm{h}$, que representa 31,2 \% da mão-de-obra da atividade (Ribeiro 2002).

As espécies florestais de produção não-madeireira mais utilizadas pelas UPA como fonte geradora de renda, consumo familiar, ou como matéria-prima para a fabricação de artefatos, estão relacionadas na Tabela 4.

Tabela 4 - Espécies florestais não-madeireiras mais exploradas nas UPA estudadas, Rio Juba, afluente do Rio Tocantíns, Cametá-PA - 2001

\begin{tabular}{lccc}
\hline Nome vulgar & Nome científico & Parte utilizada & Finalidade \\
\hline Açaí & Euterpe oleracea & Fruto & Alimentação familiar e venda \\
Açaí & Euterpe oleracea & Palmito & Venda \\
Andiroba & Carapa guianensis & Semente & Medicina caseira e venda \\
Andiroba & Carapa guianensis & Óleo & Medicina caseira e venda \\
Banana & Musa spp & Fruto & Alimentação familiar e venda \\
Buriti & Mauritia flexuosa & Fruto & Alimentação familiar \\
Buruti & Mauritia flexuosa & Tala & Esteira para secar cacau \\
Cacau & Theobroma cacao & Semente & Alimentação familiar e venda \\
Ingá & Inga paraensis & Fruto & Alimentação familiar \\
Jupati & Raphia taedigera & Tala & Instrumentos de pesca \\
Marajá & Bactris sp & Tala & Instrumentos de pesca \\
Manga & Mangifera indica & Fruto & Alimentação familiar \\
Taperebá & Spondias lutea & Fruto & Alimentação familiar \\
Virola & Virola surinamensis & Semente & Venda \\
\hline
\end{tabular}

Fonte: Ribeiro, (2002)

No manejo de criação extensiva de aves, suínos e a pesca, as operações mais utilizadas são:

- Criação extensiva de aves - é praticada por mais de 80 \% das UPA, com uso da mão-de-obra familiar e se destina quase que totalmente à alimentação da família, com comercialização de apenas alguns exemplares por apenas uma unidade de produção. As aves criadas são as espécies Cairina moschata (pato regional) e a Gallus domesticus (galinha). Raramente recebem alguma suplementação alimentar na forma de ração e, por outro lado, não contempla nenhuma prática de manejo zoo-sanitário, com vacinação ou controle de endo e ectoparasitas. 
- Criação extensiva de suínos (Sus scrofo) - é praticada por cerca de $80 \%$ das UPA, que usam a mão-de-obra familiar e se destina básicamente à alimentação. A atividade é extensiva, com os animais totalmente livres nas várzeas onde buscam a sua alimentação. Não possuem raça definida, são rústicos e adaptados às condições das várzeas. Quanto ao aspecto de controle de sanidade dos suínos e alimentação, o quadro é semelhante ao encontrado para as aves.

- Pesca de camarão regional (Macrobrachium sp.) - operação tipicamente familiar, realizada com uso de armadilhas tipo "matapí" com ocorrência quase que diária no decorrer do ano, se constituindo juntamente com o açaí, na base da alimentação das famílias.

- Pesca de peixes - realizada por meio de redes tipo "malhadeiras" e "currais", se destina à alimentação familiar. Esta operação vem diminuindo a cada ano, segundo os ribeirinhos, pela escassêz do peixe motivado pela barragem do Rio Tocantíns, em Tucuruí, que provocou a redução dos estoques e o tamanho dos peixes à jusante do lago. As espécies usualmente pescadas são a Cichlasoma sp. (acará), Leporinus fasciatus (Aracú), Anodus laticeps (branquinha), Hypophthalmus endentatus (mapará) e a Plagiocion sp. (pescada branca).

Esta atividade utiliza diariamente mão-de-obra e, ao final de um ano, demanda a média de $39,33 \mathrm{~d} / \mathrm{h}$ para a pesca de camarão regional e peixes, e $20 \mathrm{~d} / \mathrm{h}$ para a criação extensiva de aves e suínos que, juntos, consomem 59,33 d/h ano, representando $22,39 \%$ da mão-de-obra total empregada no sistema de produção.

Considerando a demanda de cerca de $264 \mathrm{~d} / \mathrm{h} / \mathrm{ano}$ com o atual manejo, fica evidenciado que os SAF’s identificados nas várzeas flúvio-marinha de Cametá, possuem potencial para ocupação da mão-de-obra existente nas UPA, indicando a possibilidade de geração de emprego produtivo com geração de renda, o que é fundamental à permanência dessas famílias na atividade rural, evitando a migração do campo para a cidade.

A produção média anual da atividade florestal madeireira expressa o quantitativo de madeira retirada de cada área para as serrarias da localidade e/ou para uso nas UPA, inclusive como lenha e/ou carvão. A produção média anual aproximada é da ordem de 135,36 $\mathrm{m}^{3}$ de madeira 
cortada, da qual 73,90 m³ é destinado à venda e 61,46 m³ são consumidos na própria UPA (Tabela 5). Em termos de participação relativa entre comercialização e consumo, identificou-se que a média anual comercializada representa 54,6 \% da produção e o consumo familiar $45,4 \%$, dos quais $28,3 \%\left(38,25 \mathrm{~m}^{3}\right)$ são usados em obras de habitação, trapiches, móveis, embarcações, etc.

A produção média anual da atividade florestal não-madeireira representa os quantitativos colhidos e/ou coletados pelas UPA no decorrer do ano 2000. Os produtos não-madeireiros mais importantes com relação à geração de renda e/ou segurança alimentar (Tabela 5), são: frutos de açaí com produção média anual por UPA de 361,5 latas de 18 litros, dos quais 60,6 \% são destinados ao consumo familiar na forma de "vinho" como parte integrante do almoço e 39,4 \% (142,5 latas) é destinada à comercialização; palmitos de açaí com uma extração média anual de 391,67 unidades, destinados à comercialização; sementes de andiroba com coleta média anual de $250 \mathrm{~kg}$ e se destina à comercialização e/ou extração de óleo nas UPA; óleo de sementes de andiroba com uma extração média anual por UPA de 57,5 litros, dos quais 95,1 \% (54,67 litros) são destinados à venda e 4,9 \% (2,83 litros), são consumidos na UPA na medicina caseira; frutos de buriti com uma coleta anual média por UPA de 77,08 latas de 18 litros de frutos, os quais são $100 \%$ utilizadas na alimentação e tem a função de substituir na entre-safra os frutos de açaí, na alimentação familiar do ribeirinho; sementes de cacau com produção média anual por UPA de $131 \mathrm{~kg}$ de sementes secas dos quais $92 \%(120,5 \mathrm{~kg})$ são destinados à comercialização e o restante $8 \%(10,5 \mathrm{~kg})$ são destinados ao consumo familiar na forma de chocolate em barras; e outros frutos como banana, ingá, manga, cupuaçu e sementes de virola, que não apresentam grande importância para comercialização e ou consumo familiar, em razão do pequeno número de exemplares existentes nos SAF's e mesmo pelos preços pagos aos produtores não serem atrativos.

A produção média anual da atividade de pesca e criação (Tabela 5), é a seguinte: produção de aves com a média anual de 20 aves abatidas, das quais $80 \%$ é destinada ao consumo (16 aves) e $20 \%$ comercializados; produção de suínos com a média anual de abate de 5,8 animais com peso-vivo médio de $30 \mathrm{~kg}$, dos quais $94,8 \%$ é destinado a alimen- 
tação (5,5 animais) e 5,2 \% é comercializado com a vizinhança; produção de $255 \mathrm{~kg}$ de camarões e $80 \mathrm{~kg}$ de peixes.

È notório o potencial de produção de alimentos dos SAF's, destinados a suprir as necessidades básicas do consumo familiar, considerando os ambientes terrestre e marinho. É igualmente relevante a forma de exploração da agrofloresta, que se processa sem o "corte raso" da vegetação para cultivos agrícolas e/ou criatórios, não havendo o "roçado" de mandioca, milho ou feijão e a prática de enriquecimento com andiroba, açaí e cacau é fundamental para a conservação e exploração socioeconômica desse ecossistema.

Tabela 5 - Produção média anual de madeiras, produtos não-madeireiros e criações, quantidades vendidas e consumidas nas UPA, Rio Juba afluente do Rio Tocantíns, Cametá-PA, 2001

\begin{tabular}{|c|c|c|c|c|c|}
\hline \multirow{2}{*}{$\begin{array}{l}\text { Produção do SAF } \\
\text { Por atividades }\end{array}$} & \multirow{2}{*}{$\begin{array}{l}\text { Unidade } \\
\text { de medida }\end{array}$} & \multicolumn{2}{|c|}{ Quantidade } & \multicolumn{2}{|c|}{ Participação - \% } \\
\hline & & Venda & Consumo & Venda & Consumo \\
\hline \multicolumn{6}{|l|}{1 - Produção madeireira } \\
\hline - Madeira em árvore & $\mathrm{m}^{3}$ & 73,90 & 61,46 & 54,60 & 45,40 \\
\hline \multicolumn{6}{|l|}{2 - Produção não-madeireira } \\
\hline - Açaí-fruto & lata-18 l & 142,50 & 219,00 & 39,40 & 60,60 \\
\hline - Açaí-palmito & unidade & 391,67 & - & 100,00 & - \\
\hline - Andiroba-semente & $\mathrm{kg}$ & 250,00 & - & 100,00 & - \\
\hline - Andiroba-óleo & 1 & 54,67 & 2,83 & 95,10 & 4,90 \\
\hline - Buriti-fruto & lata-18 l & - & 77,08 & - & 100,00 \\
\hline - Cacau-semente & $\mathrm{kg}$ & 120,50 & 10,50 & 92,00 & 8,00 \\
\hline - Banana & cacho & 8,33 & 13,50 & 38,20 & 61,80 \\
\hline \multicolumn{6}{|c|}{3 - Produção de criações e pesca } \\
\hline - Aves & unidade & 4,00 & 16,00 & 20,00 & 80,00 \\
\hline - Suínos & unidade & 0,30 & 5,50 & 5,20 & 94,80 \\
\hline - Camarões & $\mathrm{kg}$ & - & 255,00 & - & 100,00 \\
\hline - Peixes & $\mathrm{kg}$ & - & 80 & - & 100,00 \\
\hline
\end{tabular}

Fonte : Ribeiro (2002)

3.1.2 - Custos e receitas do sistema de produção agroflorestal

Os custos identificados no sistema de produção agroflorestal são, basicamente, a mão-de-obra, a aquisição de ferramentas utilizadas no manejo do sistema, os encargos sociais, depreciação e manutenção das benfeitorias, especificamente aqueles que, de alguma forma, participam do processo 
produtivo como abrigo para animais, trapiche, cascos de madeiras (barcos a motor e cascos a remo) e ainda os juros de financiamento.

O custo médio do sistema de produção agroflorestal é da ordem de $\mathrm{R} \$ 214,07 /$ ha e R $\$ 2.141,58$ por UPA. A mão-de-obra é o principal componente, representa cerca de $86 \%$ do custo total. O custo total anual do sistema por atividade, por hectare e UPA se encontra na Tabela 6 .

A renda bruta média anual originada do sistema agroflorestal representa o valor bruto da produção, inclusive a produção consumida, totalizou R\$ 3.294,25. Desse montante, R\$ 2.123,10 constitui o valor médio da produção consumida nas UPA, que representa cerca de $64 \%$ do valor bruto total da produção, enquanto que cerca de $35 \%$ da renda bruta anual média é decorrente da comercialização dos produtos da agrofloresta, que totalizaram $\mathrm{R} \$ 1.171,15$ representando os ingressos em moeda nas UPA pesquisadas (Tabela 6).

A atividade florestal madeireira por UPA gerou $R \$ 473,00$, que representa cerca de $14 \%$ da renda bruta do SAF. A atividade florestal nãomadeireira respondeu por $\mathrm{R} \$ 2.055,25$ por UPA. Desse montante, R\$ $1.224,93$, cerca de $60 \%$, é o valor bruto da produção consumida nas UPA e os restantes $R \$ 830,32$, foi a renda bruta da produção não-madeireira comercializada e que, efetivamente, são ingressos financeiros na UPA. A renda bruta média da atividade de pesca e criação de aves e suínos é da ordem de R $\$ 766,00$ por UPA, que totalizou cerca de $23 \%$ na composição da renda bruta média anual do SAF. Desse total, R\$ 355,83 representou mais de $90 \%$, sendo o valor do produto consumido pela família, e os restantes $\mathrm{R} \$ 75,00$ foi o valor médio da produção comercializada (Tabela 6).

Estabelecendo-se a relação da renda bruta média anual do SAF com o salário-mínimo de dezembro de 2000 (R\$ 180,00), verificou-se que o sistema apresentou uma renda bruta anual média de 18,3 salários mínimos por UPA ou 1,52 salário-mínimo mensal.

A renda líquida média anual das UPA pesquisadas é de $\mathrm{R} \$ 1.152,62$ (Tabela 6), que representa, anualmente, seis salários-mínimos de dezembro de 2000 ( $\mathrm{R}$ 180,00), ou seja, R \$ 96,05 por mês é a sobra para ampliação do negócio e acesso aos bens e serviços fora da UPA. 


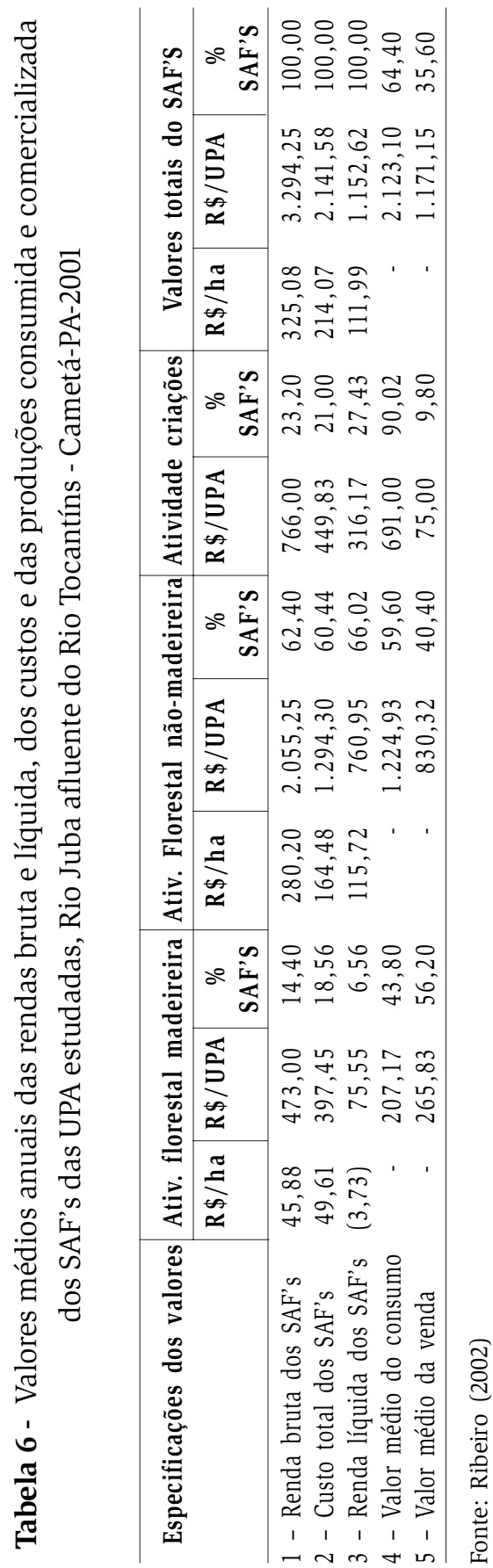




\subsection{3 - Composição da renda bruta média anual das UPA}

Dentre as diversas relações que são estabelecidas entre o rural e o urbano, vem merecendo investigações a existência de atividades nãoagrícolas desenvolvidas por membros das famílias rurais dedicadas à agricultura. A renda obtida dessas atividades não-agrícolas vai compor a renda familiar rural, aumentando a renda per capita das famílias. Tal fenômeno é conhecido como "pluriatividade" e as unidades produtivas denominadas de unidades produtivas "plurais" ou "pluriativas" (Kageyama, 2001). A autora, em seus estudos sobre as rendas não-agrícolas das famílias rurais brasileiras (excluída a Região Norte), revela que $61,5 \%$ dos domicílios agrícolas possuem rendas não-agrícolas e que tais rendas não-agrícolas são em média mais elevadas que as rendas agrícolas dos domicílios e representam em média $40 \%$ da renda total.

Neste contexto, a renda bruta média anual das UPA, representada por todos os ingressos nas UPA, inclusive o valor atribuído à produção consumida pela família, é da ordem de $\mathrm{R} \$ 6.476,92$ constituída pelas seguintes fontes e valores médios (Tabela 7):

- Sistema agroflorestal: corresponde ao valor bruto da produção ou a renda bruta anual do SAF, no valor de R\$3.294,25 respondendo por cerca de $51 \%$ da renda bruta anual da UPA;

- Aposentadoria: da ordem de $\mathrm{R} \$ 981,50$ correspondendo a $15 \%$ da renda bruta anual;

- Outras fontes: constituída por rendimentos provenientes de aluguéis de embarcações, salários, comércio e ajuda financeira de filhos, atinge o montante de $\mathrm{R} \$ 2.201,17$, correspondente a $34 \%$ da renda bruta média anual.

As rendas múltiplas que tornam as UPA pluriativas, se constituem em um fator da maior relevância e desejável, que certamente garantem a existência dessas unidades familiares, mas que, decididamente, exigem o apoio de políticas públicas adequadas à sua realidade, para a promoção do desenvolvimento sustentável. 
TABELA 7 - Elementos de formação e renda bruta anual familiar e média das UPA estudadas, Rio Juba afluente do Rio Tocantins, Cametá-PA - 2002

\begin{tabular}{c|c|r|r|r|r|r|r}
\hline \multirow{2}{*}{ UPA } & \multicolumn{2}{|c|}{ Agrofloresta } & \multicolumn{2}{c|}{ Aposentadoria } & \multicolumn{2}{c|}{ Outras fontes* } & Renda bruta \\
\cline { 2 - 8 } & Valor-R\$ & \% RBA & Valor-R\$ & \% RBA & Valor-R\$ & \% RBA & \multicolumn{1}{c}{ anual } \\
\hline UPA 1 & $4.171,50$ & 100,00 & - & - & - & - & $4.171,50$ \\
UPA 2 & $1.794,75$ & 21,00 & $1.963,00$ & 23,00 & $4.800,00$ & 56,00 & $8.557,75$ \\
UPA 3 & $5.379,10$ & 42,20 & $1.963,00$ & 15,40 & $5.407,00$ & 42,40 & $12.749,10$ \\
UPA 4 & $3.501,50$ & 100,00 & - & - & - & - & $3.501,50$ \\
UPA 5 & $3.215,50$ & 46,10 & $1.963,00$ & 28,10 & $1.800,00$ & 25,80 & $6.978,50$ \\
UPA 6 & $1.703,15$ & 58,70 & - & - & $1.200,00$ & 41,30 & $2.903,15$ \\
Média & $3.294,25$ & 50,90 & 981,50 & 15,10 & $2.201,17$ & 34,00 & $6.476,92$ \\
\hline
\end{tabular}

Fonte: Ribeiro, 2002

OBS: * UP2 - aluguel de barco, UP3 - salários da esposa e filho; UP5 - transporte e revenda de telhas e tijolos e; UP6 - ajuda financeira do filho.

\section{4 - Conclusões}

A estrutura fitossociológica dos SAF’s com 2.920 indivíduos/ha, apresentou 16 espécies que estão classificadas como comerciais, representando cerca de $92 \%$ da população total (2.692 indivíduos) o que evidencia o caracter mercantil (socioeconômico) dos SAF's.

Os SAF's, incluindo o ambiente marinho, são a base da sobrevivência e da reprodução familiar, onde os produtos extrativos não-madeireiros mais importantes são os frutos e o palmito de açaí, a semente de andiroba; os madeireiros são a virola e a andiroba; e os alimentares são o camarão, os peixes, e as aves e suínos.

A alimentação das famílias à base de produtos dos SAF's e do ambiente aquático, tem consumo diário de açaí e buriti, durante o período de coleta/colheita . Tais produtos podem ter aumento de produtividade, com melhorias no sistema de manejo atual. Porém, o consumo de peixes e de camarão têm as ofertas diminuídas em função da redução dos estoques pela pesca predatória e como conseqüência do fechamento do Rio Tocantins em Tucuruí. Essas situações precisam ser modificadas por meio de assistência técnica e financiamentos rurais apropriados à realidade local, no sentido de preservar e aumentar os estoques existentes, garantido a alimentação e renda dessas famílias e permanência no campo, o que sem dúvida, é a maneira mais barata de promover a política de 
“ fome zero” e garantir a conservação/preservação desse ecossistema Amazônico.

As operações de manejo dos SAF's realizadas ao longo do ano, denotam um potencial de ocupação de mão-de-obra e, portanto, de geração de emprego no meio rural. É necessário investimentos nas UPA e na qualificação da mão-de-obra, para um manejo agroflorestal mais apropriado, o que elevaria a produtividade atual e traria mais ocupações no meio rural.

A renda bruta proveniente da agrofloresta, denota a viabilidade econômica das UPA ao nível do salario-mínimo. Tal renda é superior a média nacional da agricultura familiar no Brasil na ordem de $\mathrm{R} \$$ 2.717,00 e ligeiramente superior à média da Região Norte de R\$ 2.904,00 (INCRA, 2000).

As fontes de rendas não-agrícola, que tornam as UPA plurais ou pluriativas, são fundamentais para a permanência das famílias na atividade e na área rural. Neste aspecto, verificou-se alguns resultados adicionais, com valores próximos aos obtidos por Kageyama (2001):

- 66,67 \% das UPA apresentam rendas oriundas de atividades nãoagrícolas e somente 33,33\% apresentam apenas a renda dos SAF's;

- 50 \% das UPA apresentam rendas de atividades não-agrícolas produtivas, (aluguel de barco, agente de saúde, professor e comércio de cerâmicas)

- Na média, a renda da atividade rural (SAF's) representa cerca de 51 $\%$ da renda bruta familiar total, e a renda não-agrícola cerca de $49 \%$;

- A renda das atividades não-agrícola e não-produtivas (aposentadoria) representa $15 \%$ da renda familiar total, na média;

- A renda das atividades não-agrícola, porém, de ocupações produtivas, em média, representam $34 \%$ da renda bruta total da UPA.

Recomenda-se como medida prioritária de curto prazo para elevar a sustentabilidade socioeconômica e ambiental das UPA, a qualificação da mão-de-obra familiar em manejo florestal sustentável de uso múltiplo, marketing dos produtos dos SAF's, gestão das UPA e políticas de assistência técnica e crédito rural, segundo a caracterização socioeconômica e ambiental do ecossistema de várzea, especialmente para a agricultura de base familiar. 


\section{5 - Agradecimentos}

Agradecemos o apoio recebido da Coordenação do Curso de Mestrado em Ciências Florestais da UFRA (ex-FCAP), da EMATER-PA, da CEPLAC CAMETÁ, do Eng ${ }^{\circ}$ Ftal. Sílvio dos Santos e dos agricultores familiares Raimundo Lousado, Benedito Otávio, Maria Amélia, Bráulio Leão, Wilson Pinto, e Manoel Furtado.

\section{6 - Referências Bibliográficas}

FURTADO, L. G. Riqueza e exploração da pesca: In: IBAMA. Amazônia: uma proposta interdisciplinar de educação ambiental: temas básicos. Brasília, DF: 1994. 334 p. p. $264-265$.

HOFFMANN, R.; ENGLER, J. J. de, C.; SERRANO, O.; THAME, A. C. de, M. ; NEVES, E. M. Administração da empresa agrícola. 2. ed. São Paulo: Pioneira, 1978. 325p.

IMAZON. O Pará no século XXI: oportunidades para o desenvolvimento sustentável. Belém, 1998. 83 p.

KAGEYAMA, A. As múltiplas fontes de renda das famílias agrícolas brasileiras. Agricultura em São Paulo, São Paulo, v. 48. n. 2, p. 57-69, 2001.

INCRA. Retrato da agricultura familiar - o Brasil redescoberto. Brasília, DF: 2000. 74p.

QUEIROZ, W. T. Análise de fatores ("facto analysis") pelo método da máxima verossimilhança: aplicação ao estudo da estrutura de florestas tropicais. 1994. 112 p. Tese (Doutorado em Agronomia) ESALQ, Piracicaba, 1994.

TOURINHO, M. M.; NOGUEIRA, E. L. S. Uso da terra e sistemas de produção nas várzeas flúvio- marinhas da Amazônia. In: CONGRESSO BRASILEIRO DE ECONOMIA E SOCIOLOGIA RURAL, 37., 1999, Foz do Iguaçu. Anais ... Brasília, DF: SOBER, 1999.

RIBEIRO, R. N. da, S. R. Avaliação do potencial de sustentabilidade de unidades produtivas agroflorestais em várzeas de influência flúvio-marinha, Cametá-Pará. 2002. 194 f. Dissertação (Mestrado em Ciências Florestais) FCAP, Belém, 2002. 
152 - Análise Exploratória da Socioeconomia de Sistemas Agroflorestais em Várzea Flúvio-Marinha, Cametá-Pará, Brasil

LOUREIRO, A. A.; SILVA, M. F. da. Cátalago das madeiras da Amazônia. Belém: SUDAM, 1968. v. 1, 433p.

SHANLEY, P.; CYMERYS, M.; GALVÃO, J. Frutíferas da mata na vida amazônica. Belém: [s. n.], 1998. 127p.

Recebido em abril de 2003 e revisto em junho de 2003. 